\title{
OPTIMAL TARIFFS AND FINANCIAL ASSETS
}

\author{
Hal R. VARIAN * \\ University of Michigan, Ann Arbor, MI 48109, USA
}

Received August 1987, final version received April 1988

\begin{abstract}
Many countries seem to discourage international financial transactions by their residents, despite the benefits from portfolio diversification that such transactions provide. If a country is small relative to the size of world financial markets, such restrictive policies are probably counterproductive, but a country that is large enough to influence world prices may find it advantageous to engage in such practices. In this paper, I describe a simple model of optimal taxation of risky foreign assets and examine the implications for risk sharing.
\end{abstract}

Keymords: Finance, taxation, international finance.

\section{Introduction}

It has been widely observed that investors' financial portfolios seem to be overly concentrated in domestic securities, despite the beneficial reduction in risks that are possible from international portfolio diversification. See for example, Feldstein and Hartman (1980), Obstfeld (1985), and Summers (1985). Indeed, government tax policy in most countries seems to actively discourage international diversification.

The Japanese government, for example, has placed restrictions on banks' net foreign exchange positions, regulated banks' issue of Certificates of Deposit abroad, limited the amount of foreign assets held by international investors, regulated long-term Euro-yen loans, and so on. Investment trusts. insurance companies, and other institutions in Japan were not even allowed to hold foreign securities until the early seventies, and foreigners were not allowed to hold many types of Japanese financial instruments until the late seventies. ${ }^{1}$

The Japanese case is extreme, but it is common to see special witholding taxes on dividends paid to foreigners, deductions rather than credits for foreign taxes paid, and other fiscal policies which tend to discourage international capital flows. Most countries have, at least at some time in their

- This paper was prepared for the symposium on Financial Investment in the U.S. and Japan held at the New York University Graduate School of Business Administration, April 27 and 28, 1987. I wish to thank Roger Gordon, Theodore Bergstrom, and Gary Saxonhouse for useful discussions about the topics considered in this paper.

${ }^{1}$ In 1983-1984 Japan agreed to a number of measures designed to liberalize these sorts of restrictions. See Frankel (1984) for a summary of the economic impact of these policies. 
histories, engaged in large-scale intervention in financial markets in ways that appear to be designed to discourage trade in foreign assets. In some cases. such policies appear to be motivated by short-run fluctuations in exchange rate movements. But in other cases, it appears that governments may try to discourage trade in foreign assets as part of a long-run policy.

When we consider the riskiness inherent in international financial markets, long-run attempts to discourage international portfolio diversification seem especially perverse. Grubel (1968), Levy and Sarnat (1970). Solnik (1974). Grauer and Hakảnsson (1987) and many other authors have pointed out that major stock indices in different countries often have rather low correlations with each other, and that this can be exploited in the construction of optimal portfolios. For a recent discussion see section 2 of the comprehensive survey by Adler and Dumas (1983).

In the case of the U.S. and Japan, for example, the simple correlation of monthly price changes for the major stock market indices during the period 1971-1979 was 0.33. In some cases, such as the U.S. and the U.K.. the correlations were even negative. Such small correlations allow for substantial risk reduction via diversification. To the extent that other countries' risks are not perfectly correlated with domestic risks, international investment offers highly beneficial diversification. Why would countries want to discourage such portfolio diversification?

Gordon and Varian (1986) argue that such policy intervention may be an attempt to exploit market power in international financial markets. Even though any single security may be a small fraction of total world wealth, the total securities offered by a large country such as the United States or Japan may represent a sizable fraction of world wealth. To the extent that risks faced by different countries are independently distributed, each country's securities offer a unique source of diversification. Thus, each country faces a downward sloping demand for its risky sccurities, and therefore may find it beneficial to attempt to exploit its market power.

The tax policy in such a large country may be adjusted so as to exploit the downward sloping demand for its securities. By artificially restricting trade in its domestic securities, a country can raise the world price of those securities and thus increase the expected utility of its residents. Of course, if all countries attempt to exploit their market power, the resulting restriction in trade may make everyone worse off. Each country's attempt to shift the terms of trade in financial assets in its favor results in an inefficient distribution of risk bearing.

The optimal tariff results of international trade describe how countries can set tariffs and export controls so as to improve the terms of trade they face with respect to goods; we wish to apply the same notions to financial assets. The specific structure of demand functions for financial assets gives a special structure to the standard 'large country' results of international trade theory and allows for a more detailed analysis of the resulting equilibrium. 
Gordon and Varian (1986) provide a detailed policy analysis of the optimal tariff in world financial markets. In this paper, I derive a formula for the optimal tariff in general circumstances and then apply this formula to the special case of financial markets. The particular case examined is a significantly simpler version of the Gordon-Varian model which allows for a relatively easy examination of the effects of tax policy on international risk-sharing.

\section{A general formula for the optimal tariff}

We begin by examining the optimal tariff for a single large country. This is, of course, a classic problem in international trade, and has been considered by a number of authors, among them Scitovsky (1942) and Graaf (1949). For a modern discussion, see Dixit and Norman (1980) and Woodland (1982). The closest treatment to our own is that of Bergstrom (1982), except that we use duality and focus on the representative consumer case.

Most of the existing literature on optimal tariffs seems to implicitly treat the case of an export tariff. In this case it is natural to take the objective function of the exporting country to be the maximization of tariff revenue. If. however, one examines the more economically natural case of a tariff on imports, maximization of tariff revenue is no longer an appropriate objective. In this case, the importing country must take into account not only the tariff revenue, but also the reduction in domestic welfare resulting from facing higher world prices. ${ }^{2}$ In order to compute the optimal tariff, the marginal gains from the tariff revenue must be balanced against the marginal losses to domestic consumers and producers from the distorted prices.

Consider a country which is a large consumer of a particular imported good. This country wants to choose a tariff on this imported good that makes its consumers as well off as possible, given the demand and supply of the good by the rest of the world. Denote the world price of the good by $p$ and the tax on the good by $t$. If the country in question is large enough to have significant market power, the equilibrium price of the good will depend on the tax imposed on it, so we indicate this dependence by $p(t)$.

The indirect utility of a representative consumer in the country under consideration is denoted by $v(p, y)$ where $y$ is the consumer's income. We assume that this country will return the tariff revenue to the representative consumer in a lump-sum manner. We denote this tariff revenue by

$$
r(t)=t x(p(t)+t)
$$

2 Even in the case of an export tariff, there will typically be a reduction in producer profits due to distorted prices. 
where $x(\cdot)$ is the domestic consumer's demand for the good. (In general, the demand for the good will depend on the consumer's money income, which will in turn depend on the magnitude of the rebated tariff revenue. We ignore this general equilibrium income effect in what follows.)

The optimal tariff problem then becomes

$$
\max _{t} v(p(t)+t, y+r(t)) \text {. }
$$

The first-order condition for this problem is

$$
\frac{\partial v}{\partial p}\left[\frac{\partial p}{\partial t}+1\right]+\frac{\partial v}{\partial y} \frac{f \partial r}{\partial t}=0 .
$$

Dividing this equation by $\partial v / \partial y$ and applying Roy's identity gives

$$
-x\left[\frac{\partial p}{\partial t}+1\right]+\frac{\partial r}{\partial t}=0 .
$$

Differentiating the definition of revenue given in (1) yields

$$
\frac{\partial r}{\partial t}=t \frac{\partial x}{\partial p}\left[\frac{\partial p}{\partial t}+1\right]+x .
$$

Substitute this into (2) and rearrange to find

$$
\left[t \frac{\partial x}{\partial p}-x\right] \frac{\partial p}{\partial t}+t \frac{\partial x}{\partial p}=0 .
$$

It is useful to divide this expression by $x$ and convert to elasticity form

$$
\left[\frac{t}{p} \epsilon-1\right] \frac{\partial p}{\partial t}+\frac{t}{p} \epsilon=0 .
$$

Solving for $t / p$ gives us

$$
\frac{t}{p}=\frac{1}{\epsilon}\left[\frac{\partial p / \partial t}{1+\partial p / \partial t}\right]
$$

Hence the optimal tariff on good $i$ is inversely proportional to its elasticity of demand, weighted by the responsiveness of the world price to the tariff. If a country is only a small part of world trade in the good in question, $d p / d t$ will be essentially zero, so that the optimal tariff in such a case is zero. But if a country is large enough so that its tax policy influences the world price of the good, then it will pay it to set a tariff to exploit this market power.

In order to derive an expression for the bracketed term, we let $X(p)$ be the demand for the good by the rest of the world and $S(p)$ be the world supply. Demand equals supply then can be written as

$$
x(p(t)+t)+X(p(t))=S(p(t)) .
$$

Differentiating with respect to $t$ and solving for $\partial p / \partial t$ gives us

$$
\frac{\partial p}{\partial t}=-\frac{\partial x / \partial p}{\partial D / \partial p-\partial S / \partial p},
$$


where $D=x+X$ is total world demand. Multiplying the numerator and denominator of this expression by $p / D$, and recognizing that $D=S$ in equilibrium allows us to write

$$
\frac{\partial p}{\partial t}=\frac{s \epsilon}{\epsilon_{S}-\epsilon_{D}}
$$

where $\epsilon$ is the elasticity of country $i$ 's demand for the good, $s$ is the share of the country's consumption of the good as a fraction of world consumption, $\epsilon_{D}$ is the elasticity of world demand and $\epsilon_{S}$ is the elasticity of world supply.

Substituting eq. (4) into (3) and simplifying we have the final formula for the optimal tariff:

$$
\frac{t}{p}=\frac{s}{s \epsilon+\epsilon_{S}-\epsilon_{D}}
$$

The optimal tariff as a fraction of the world price will depend on the country's share of world demand. For a country that is a small fraction of world demand, the optimal tariff is near zero. But for a country with a significant share of world demand, the optimal tariff may be quite large.

\section{Financial assets}

We now apply the calculations of the last section to a simple model of world trade in financial assets. We will calculate the optimal tariff directly and also by applying formula (3). It will be seen that applying the optimal tariff formula will allow for a cleaner and more easily generalized analysis.

We suppose that there are two countries, 1 and 2. Each country $i$ is endowed with a technology that generates a random output in period 2 denoted by $\tilde{V}_{i}$. For convenience, we assume that the certain rate of interest is zero and, for computational simplicity, that $\tilde{V}_{i}$ are independent and normally distributed with mean $V_{i}$ and variance $\sigma_{i}^{2}$.

We assume that there is an international market in these risky assets, and denote the before-tax price of asset $i$ by $p_{i}$. Country $i$ may choose to tax its resident's purchases of country $j$ 's security with a specific tax of magnitude $t_{i j}$. The revenues from this tax are returned to the residents as a lump sum.

Let $x_{i j}$ denote country $i$ 's holdings of country $j$ 's security. Then the (random) wealth in country 1 , say, will be given by

$$
\tilde{W}_{1}=W_{0}+T+p_{1} x_{11}-\left(p_{2}+t_{12}\right) x_{12}+x_{11} \tilde{V}_{1}+x_{12} \tilde{V}_{2},
$$

where $T=t_{12} x_{12}$ is the lump sum tax rebate. For future reference we note that the mean and variance of wealth are given by

$$
\begin{aligned}
& W=W_{0}+T+\left(V_{1}-p_{1}\right) x_{11}+\left(V_{2}-p_{2}-t_{12}\right) x_{12}, \\
& \sigma_{W}^{2}=x_{11}^{2} \sigma_{1}^{2}+x_{12}^{2} \sigma_{2}^{2} .
\end{aligned}
$$


The citizens of each country are assumed to have identical von Neumann-Morgenstern expected utility functions with constant absolute risk aversion of $a$. It is well known that the assumption of constant risk aversion. in conjunction with normality, implies that individuals will maximize a linear function of mean and variance of wealth; that is, a mean-variance utility function of the form $W-(a / 2) \sigma_{W}^{2}$.

Hence the maximization problem facing individuals in country 1 before any taxes are imposed is

$$
\max W_{0}+T+\left(V_{1}-p_{1}\right) x_{11}+\left(V_{2}-p_{2}\right) x_{12}-(a / 2)\left(x_{11}^{2} \sigma_{1}^{2}+x_{12}^{2} \sigma_{2}^{2}\right) .
$$

The first-order conditions for the optimal portfolio choice are

$$
\begin{aligned}
& V_{1}-p_{1}-a x_{11} \sigma_{1}^{2}=0, \\
& V_{2}-p_{2}-a x_{12} \sigma_{2}^{2}=0 .
\end{aligned}
$$

Solving these two equations gives us the asset demand functions for country 1 :

$$
\begin{aligned}
& x_{11}=\frac{V_{1}-p_{1}}{a \sigma_{1}^{2}}, \\
& x_{12}=\frac{V_{2}-p_{2}}{a \sigma_{2}^{2}} .
\end{aligned}
$$

Note that the demand functions are independent of the prices of other goods and income, which were assumptions underlying the derivation of the optimal tariff formula derived above.

Let us now solve for the world equilibrium in the absence of any distorting taxes. The demand equals supply condition for asset 1 is

$$
\begin{aligned}
& x_{11}+x_{21}=1, \\
& \frac{V_{1}-p_{1}}{a \sigma_{1}^{2}}+\frac{V_{1}-p_{1}}{a \sigma_{1}^{2}}=1 .
\end{aligned}
$$

Solving, we have the equilibrium price of asset 1 ,

$$
p_{1}^{*}=V_{1}-\frac{a \sigma_{1}^{2}}{2}
$$

Substituting back into the demand functions for asset 1 gives us the equilibrium demands for asset 1 ,

$$
x_{11}^{*}=x_{21}^{*}=\frac{1}{2} \text {. }
$$

The equilibrium in the absence of distorting taxes involves equal risk sharing: each country holds a fully diversified portfolio consisting of equal shares of each other country's risky asset. 


\section{Equilibrium with distorting taxes}

Suppose now that country 1 puts a tax on its citizens' purchases of foreign assets. This raises the price of country 2 's security to $p_{2}+t_{12}$. Let us solve for the effect of this tax on the equilibrium price and quantity demanded of security 2 .

Demand equals supply takes the form

$$
\begin{aligned}
& x_{12}+x_{22}=1, \\
& \frac{V_{2}-p_{2}-t_{12}}{a \sigma_{2}^{2}}+\frac{V_{2}-p_{2}}{a \sigma_{2}^{2}}=1 .
\end{aligned}
$$

Solving for $p_{2}^{*}$ and the equilibrium quantities demanded yields

$$
\begin{aligned}
& p_{2}^{*}=V_{2}-\frac{a \sigma_{2}^{2}+t_{12}}{2}, \\
& x_{12}^{*}=\frac{1}{2}-\frac{t_{12}}{2 a \sigma_{2}^{2}}, \\
& x_{22}^{*}=\frac{1}{2}+\frac{t_{12}}{2 a \sigma_{2}^{2}} .
\end{aligned}
$$

Suppose now that country 1 recognizes its influence on the market price of asset 2 . It would generally make sense for it to set the tax on asset 2 so as to maximize the utility of its citizens, taking into account its influence on the market price of asset 2 .

This optimal tariff problem can be written as

$$
\begin{aligned}
& \max W_{0}+T+\left(V_{1}-p_{1}\right) x_{11}+\left(V_{2}-p_{2}-t_{12}\right) x_{12}-(a / 2)\left(x_{11}^{2} \sigma_{1}^{2}+x_{12}^{2} \sigma_{2}^{2}\right) \\
& \text { such that } \quad x_{12}=\frac{1}{2}-\frac{t_{12}}{2 a \sigma_{2}^{2}}, \\
& p_{2}=V_{2}-\frac{a \sigma_{2}^{2}+t_{12}}{2}, \\
& T=t_{12} x_{12} .
\end{aligned}
$$

The first two constraints summarize the influence of country 1's tax policy on the price and quantity traded of country 2's asset while the last constraint is simply the definition of tax revenues. Substituting the constraints into the objective function, dropping the inessential constants, and rearranging yields

$$
\max \frac{\left(a \sigma_{2}^{2}+t_{12}\right)\left(a \sigma_{2}^{2}-t_{12}\right)}{4 a \sigma_{2}^{2}}-\left(\frac{a \sigma_{2}^{2}}{2}\right)\left(\frac{a \sigma_{2}^{2}-t_{12}}{2 a \sigma_{2}^{2}}\right)^{2} .
$$


After some more manipulation and elimination of inessential constants, we reduce the problem to

$$
\max t_{12} a \sigma_{2}^{2}-\frac{3}{2} t_{12}^{2},
$$

which has the solution

$$
t_{12}^{*}=\frac{a \sigma_{2}^{2}}{3} \text {. }
$$

Note that the optimal tariff depends only on the variance of the foreign asset - terms involving the expected return have dropped out. This is because it is only the variance of the foreign asset that provides something unique namely, the diversifiable risk. That is, it is the independent riskiness of the foreign asset that makes it less than a perfect substitute for domestic assets, and therefore leads to a less than perfectly elastic demand for it.

Substituting back into the asset demand functions gives us the equilibrium trades:

$$
\begin{aligned}
& x_{12}=\frac{1}{3}, \\
& x_{22}=\frac{2}{3} .
\end{aligned}
$$

Recall that in the no-tariff case, the efficient allocation of risk bearing was for each country to hold half of each country's risk. Here, the attempt to exploit market power in each risky asset has lead to country 1 holding only a third of country 2's risky asset.

Of course, country 2 can do the same calculations. Since country 2 has a monopsony position in providing a buyer for country 1's risk, country 2 may be expected to discourage its residents from holding the risky asset of the other country. The net result is that each country only ends up holding a third of the other country's risk. The 'optimal' tariff on country 2's security has led to an inefficient allocation of risk bearing.

\section{A simpler calculation}

In the previous section we have calculated the optimal tariff directly. However, it is much easier to use the formula for the optimal tariff derived via duality in section 2 , which we restate here using the notation of the last section:

$$
\frac{t_{12}}{p_{2}}=\frac{1}{\epsilon}\left[\frac{\partial p_{2} / \partial t_{12}}{1+\partial p_{2} / \partial t_{12}}\right]
$$

Using eq. (6) we see that $\partial p_{2} / \partial t_{12}=-1 / 2$. The elasticity of demand can be derived from the expression for the demand function. We have

$$
\epsilon=\frac{p_{2}}{x_{2}} \frac{\delta x_{2}}{\delta p_{2}}=-\frac{1}{a \sigma_{2}^{2}} \frac{p_{2} a \sigma_{2}^{2}}{V_{2}-p_{2}-t_{12}}=\frac{p_{2}}{V_{2}-p_{2}-t_{12}} \text {. }
$$


Substituting into the formula for the optimal tax gives us

$$
\frac{t_{12}}{p_{2}}=\frac{V_{2}-p_{2}-t_{12}}{p_{2}}
$$

or

$$
t_{12}=\frac{V_{2}-p_{2}}{2} .
$$

The expression $V_{2}-p_{2}$ can be interpreted as the risk premium - the difference between the expected value of the asset and its market price. Thus we see that the optimal tax in this case is simply half of the risk premium.

Using the equilibrium value of $p_{2}$ from eq. (6), we have

$$
t_{12}=\frac{a \sigma_{2}^{2}+t_{12}}{4}
$$

which can be solved to give

$$
t_{12}=\frac{a \sigma_{2}^{2}}{3}
$$

just as we derived in section 4 .

\section{Extensions of the symmetric case}

The symmetric country case that we have examined up until now is a very special one. But armed with the general formula for the optimal tax. we are in a position to easily examine generalizations of the symmetric case to somewhat more realistic situations.

\subsection{Different degrees of risk aversion}

First, we consider the case where the two countries have different degrees of risk aversion. Now the demand equals supply condition for world equilibrium takes the form

$$
\frac{V_{2}-p_{2}-t_{12}}{a_{1} \sigma_{2}^{2}}+\frac{V_{2}-p_{2}}{a_{2} \sigma_{2}^{2}}=1
$$

It follows that the equilibrium price is

$$
p_{2}=V_{2}-\frac{a_{2} t_{12}+\sigma_{2}^{2} a_{1} a_{2}}{a_{1}+a_{2}} \text {. }
$$

Hence

$$
\frac{\partial p_{2}}{\partial t_{12}}=-\frac{a_{2}}{a_{1}+a_{2}}
$$


Substituting this into the formula for the optimal tax. we find that

$$
t_{12}=\frac{a_{2}}{a_{1}+a_{2}}\left(V_{2}-p_{2}\right) \text {. }
$$

Note that country l's tax on country 2 's risky asset is proportional to country 2's degree of risk aversion - the more risk averse country 2 is, the more heavily country $l$ wants to tax its risky asset. This fact did not emerge from the symmetric case.

Intuitively, the more risk averse country is more anxious to shift its risk. and is therefore more susceptible to exploitation by the other country. That is, the more risk averse country will have a more inelastic net supply of its asset to the world markets and will be willing to accept worse terms of trade simply to shift some of its risk to world markets.

\subsection{Several countries}

Another case of interest is the case of $n$ countries. In this case, we suppose that country $i$ taxes country 2's asset at a rate of $t_{i 2}$ and solve for country l's optimal tax rate.

In this case, demand equals supply takes the form

$$
\sum_{i \neq 2} \frac{V_{2}-p_{2}-t_{i 2}}{a \sigma_{2}^{2}}+\frac{V_{2}-p_{2}}{a \sigma_{2}^{2}}=1
$$

which is easily solved for $p_{2}$ :

$$
p_{2}=V_{2}-\frac{\sum_{i \neq 2} t_{i 2}+a \sigma_{2}^{2}}{n} \text {. }
$$

It follows that $d p_{2} / d t_{12}=-1 / n$, and substituting this expression into the formula for the optimal tax, we find that

$$
t_{12}=\frac{V_{2}-p_{2}}{n} \text {. }
$$

Thus, country 1 taxes only $1 / n$th of the risk premium on country 2 's risky asset. Substituting the equilibrium value of $p_{2}$, this expression reduces to

$$
t_{12}=\frac{\sum_{i \neq 2} t_{i 2}+a \sigma_{2}^{2}}{n^{2}} .
$$

In the symmetric solution, all countries choose the same tax rate so that $t_{12}=t_{i 2}$, and we have

$$
t_{12}=\frac{a \sigma_{2}^{2}}{n^{2}-n+1} .
$$

Thus as the number of countries increases, the tax rate declines at a rate proportional to the square of the number of countries. This calculation 
suggests that the gains from attempting to use taxes to exploit market power diminish rapidly as more countries adopt this policy.

\section{Summary}

We have derived a general formula for an optimal tariff using duality theory and applied it to the optimal taxation of internationally traded financial assets. The computations involved are much simpler than those involved in using the direct method.

We have seen that the optimal tax in our framework will be a tax on the risk premium. The size of the tax will be directly proportional to the riskiness of the foreign assets and the degree of risk aversion of the exporting country. As the number of countries engaged in this tactic increases, the size of the optimal tax will decrease in proportion to the square of the number of countries. Thus the gains from exploitation rapidly diminish as the number of participants increases.

\section{References}

Adler, M. and B. Dumas, 1983, International portfolio choice and corporate finance: A survey. Journal of Finance 38, no. 3, 925-984.

Bergstrom. T., 1982, On capturing oil rents with a national excise tax. American Economic Review 72, 194-201.

Dixit, A. and V. Norman, 1980, Theory of international trade (Cambridge University Press, Cambridge).

Gordon, R. and H. Varian, 1986, Taxation of asset income in the presence of a world securities market, Journal of International Economics, forthcoming.

Graaf, J. V. de, 1949, On optimal tariff structures, Review of Economic Studies 17. 47-59.

Grauer, K. and N. Hakảnsson, 1987, Gains from international diversification: 1968-85 returns on portfolios of stocks and bonds, Journal of Finance 42, no. 3, 721-741.

Grubel, H., 1968, International diversified portfolios: Welfare gains and capital flows. American Economic Review 58, 1299-1314.

Feldstein, M. and D. Hartman, 1980, The optimal taxation of foreign source investment income, The Economic Journal 90, 314-329.

Frankel, J., 1984, The yen/dollar agreement: Liberalizing Japanese capital markets (Institute for International Economics. Washington, DC).

Horwell, D. and I. Pearce, 1970, A look at the structure of optimal tariff rates. International Economic Review 11, 147-161.

Levy, H. and M. Sarnat, 1970, International diversification of investment portfolios. American Economic Review 60, 668-675.

Obstfeld, M., 1985, Capital mobility in the world economy: Theory and measurement. NBER working paper no. 1692.

Scitovsky, T., 1942. A reconsideration of the theory of tariffs, Review of Economic Studies 9. $89-110$.

Solnik, B., 1974, The international pricing of risk: An empirical investigation of the world capital market structure. Journal of Finance 29, 48-54.

Solnik. B., 1974, Why not diversify internationally rather than domestically?. Financial Analysts Journal $30,48-54$.

Summers, L., 1985. Taxation and international competitiveness. Mimeo.

Woodland, A., 1982. International trade and resource allocation (North-Holland. Amsterdam). 